Article

\title{
Development of the Korean Climate Change Vulnerability Assessment Tool (VESTAP)—Centered on Health Vulnerability to Heat Waves
}

\author{
Kwan-Young $\mathrm{Oh}^{1}{ }^{1}$, Moung-Jin Lee ${ }^{1, *}$ and Seong-Woo Jeon ${ }^{2, *}$ \\ 1 Center for Environmental Assessment Monitoring, Korea Environment Institute (KEI), 370 Sicheong-daero, \\ Sejong 30147, Korea; ohky@kei.re.kr \\ 2 Divison of Environmental Science \& Ecological Engineering, Korea University, 145 Anam-ro, Seongbuk-gu, \\ Seoul 02841, Korea \\ * Correspondence: leemj@kei.re.kr (M.-J.L.); eepps_korea@korea.ac.kr (S.-W.J.); \\ Tel.: +82-44-415-7314 (M.-J.L.); +82-2-3290-3043 (S.-W.J.)
}

Received: 2 May 2017; Accepted: 19 June 2017; Published: 24 June 2017

\begin{abstract}
The purpose of this study was to develop a Korean climate change vulnerability assessment tool, the Vulnerability Assessment Tool to build Climate Change Adaptation Plan (VESTAP). Based on Intergovernmental Panel on Climate Change methodology, VESTAP can be used to evaluate Korea's vulnerability to major climate impacts (including 32 conditions in 8 categories). VESTAP is based on RCP 4.5/8.5 scenarios and can provide evaluation results in 10-year intervals from the 2010s to 2040s. In addition, this paper presents the results of a case study using VESTAP for targeted assessment of health vulnerability to heat waves under the RCP 8.5 scenario for the 2040s. Through vulnerability assessment at the province level in South Korea, Daegu Metropolitan City was identified as the most vulnerable region. The municipality and submunicipality levels of Daegu were also assessed in separate stages. The results indicated that Pyeongni 3-Dong in Seo-Gu was most vulnerable. Through comprehensive analysis of the results, the climate exposure index was identified as the greatest contributor to health vulnerability in Korea. Regional differences in climate exposure can be moderated by social investment in improving sensitivity and adaptive capacity. This study is significant in presenting a quantitative assessment of vulnerability to climate change by the administrative unit in South Korea. The results of this study are expected to contribute to the efficient development and implementation of climate change adaptation policies in South Korea.
\end{abstract}

Keywords: adaptive capacity; climate change; health vulnerability; heat wave; IPCC AR4; vulnerability assessment

\section{Introduction}

Since the 1970s, the world has achieved economic growth through rapid industrialization. In consequence of the rapid industrialization, the world has faced various environmental issues including environmental degradation. Then, in the 1990s, many countries set sustainability as a higher priority in order to avoid various environmental issues. Climate change has emerged as one of the most pressing environmental issues facing the world today [1]. According to the Fifth Assessment Report by the Intergovernmental Panel on Climate Change (IPCC) [2], it is predicted that the average temperature of the earth will increase by $3.7^{\circ} \mathrm{C}$ and sea level will rise by $63 \mathrm{~cm}$ before the end of this century unless emissions are reduced [2]. Climate change may have far-reaching consequences across human societies, affecting states, communities, and industries; thus, the assessment of vulnerability and adaptation to climate change is necessary to minimize the potential damage caused by climate change and to enhance sustainable development [3,4]. 
The concept of vulnerability to climate change has been defined by the IPCC [3], and this definition is used most commonly [5]. Houghton [6] defined vulnerability to climate change as the degree to which a system is susceptible to and unable to cope with the adverse effects of climate change. Moss [7] defined the concept narrowly and conducted a vulnerability assessment as a function of biophysical vulnerability and socio-economic adaptive capacity; the Vulnerability-Resilience Indicator Prototype model (VRIP model) was applied, which uses sensitivity and adaptive capacity indices. Brooks [8] conducted a study to establish indices for vulnerability assessment by country and suggested indices of vulnerability and adaptive capacity at the country level. Later, in its Fourth Assessment Report [1], the IPCC further elaborated on the concept of assessing vulnerability to climate change using a weighted function of climate exposure, sensitivity, and adaptive capacity. Climate exposure here refers to climate stimuli that affect systems, and sensitivity indicates a system that responds sensitively to climate stimuli. Adaptive capacity is the ability of a system to adjust to climate stimuli [9]. These concepts, however, are so complex that it is difficult to directly calculate them into indices; thus, they are estimated indirectly via proxy variables. The proxy variables used in vulnerability assessment differ among countries and even regions within a country; therefore, it is necessary to conduct research to select vulnerability assessment conditions that reflect the characteristics of each country and region [10]. Vulnerability assessment at the country level plays a crucial role in establishing national climate change adaptation policies, as policy implementation and priority can be determined through a relative vulnerability assessment that takes into account the capacity of the target region [11,12]. The Stockholm Environment Institute (SEI) developed a Vulnerability Assessment Tool suited to the characteristics of a region that provides assessment results in terms of vulnerability as well as information on the potential advantages of the adaptation option [13]. The United Nations Framework Convention on Climate Change (UNFCCC) compendium provides tools and data used by Non-Annex I Parties to the UNFCCC to assess vulnerability to climate change [14]. The United States Geological Survey (USGS) offers a web-based vulnerability assessment tool, Climate Registry for the Assessment of Vulnerability (CRAVe), and provides results of climate change vulnerability assessment of threats to nature and natural resources in the US [15]. The Climate Change Integrated assessment Methodology for cross-Sectoral Adaptation and Vulnerability in Europe (CLIMSAVE) project developed a web-based tool to assess climate change and adaptation options for Europe [16]. This tool allows stakeholders to assess quantitatively climate change vulnerabilities for a range of sectors: agriculture, forests, biodiversity, coasts, water resources, and urban development. The Global Facility for Disaster Reduction and Recovery (GFDRR) provides the results of climate change vulnerability assessments for developing countries, as well as country profiles that include various data sets such as precipitation, temperature change, and vulnerability indices $[17,18]$.

In Korea, to date, these tools have not yet been applied in a practical way due to a lack of standards set by the government for methodologies, proxy variables, and weighting factors. To this end, we suggest 455 proxy variables and weighting factors for 32 vulnerability assessment items in 7 categories, based on the concept of vulnerability assessment defined in the IPCC's Fourth Assessment Report [1]. In addition, a GIS-based tool, known as the Vulnerability Assessment Tool to build Climate Change Adaptation Plan (VESTAP) was developed for the automation and visualization of vulnerability assessment. The 455 proxy variables are calculated from RCP scenario and current statistical data such as social, economic and geographic. These proxy variables are classified into climate exposure, sensitivity and adaptation ability indexes. For the climate exposure index, VESTAP utilizes RPC 4.5 and 8.5 scenarios that were refined by the Korea Meteorological Administration based on HadGEM2, a climate projection model from the UK Met Office. The climate exposure variables were divided temporally into 10-year intervals from the 2000s to the 2040s. Geographically, the proxy variables were divided into "Province level", "Municipality level", and "Submunicipality level" groups. Province-level divisions include metropolitan areas and provinces (Do), which are segmented into municipalities such as cities ( $\mathrm{Si}$ ), counties (Gun), and districts (Gu). Submunicipalities, 
as the smallest administrative units in South Korea, include towns (Eup), townships (Myeon), and neighborhoods (Dong).

Many researchers have estimated that the occurrence of heat waves and the adverse effects associated with them will increase due to global warming $[19,20]$. Heat waves lead to physiological changes in the human body, and are a direct cause of increased heat-related illnesses and deaths [21-23]. Extreme heat wave events have been identified as the deadliest weather-related hazard in many nations [24]. In particular, extreme heat wave events caused 80,000 deaths in Europe in 2003 [25] and 54,000 deaths in Russia in 2010 [26]. Kysely [27] conducted a study on the annual number of deaths in Korea caused by extreme weather events from 1901 to 2008; heat waves were found to be the dominant cause of death, killing 3384 people. In other words, the threat to health due to heat waves is the most serious problem associated with extreme weather in Korea. The adverse health effects that result from extreme heat waves can be prevented. Some nations that implement heat wave response measures during heat waves have experienced decreases in the incidences of heat-related illnesses and deaths [28]. Through vulnerability assessment for heat waves, each country and city can formulate a heat wave response plan. The published literature on vulnerability to heat waves is substantial, but quantitative assessments across South Korea have been relatively rare [29]. Therefore, we conducted a case study on health vulnerability to heat waves across South Korea using VESTAP. This case study was divided into three stages depending on the administrative unit. During the first stage, vulnerability was assessed at the level of "Provinces" across the entire area of South Korea. In the second stage, vulnerability assessment was conducted at the level of "Municipalities", focusing on the province that showed the highest vulnerability in the first stage. During the third stage, vulnerability assessment was carried out at the level of "Submunicipalities", focusing on the municipality that showed the highest vulnerability in the second stage.

The purposes of this study were as follows. First, we aimed to develop the GIS-based VESTAP system to assess climate change vulnerability throughout Korea at various administrative levels. At this time, VESTAP was constructed using a GIS system and was based on 7 categories and 32 vulnerability conditions, using methodologies described in previous studies. Second, as a case study, a health vulnerability assessment was carried out for heat waves, and the conditions used for assessment were analyzed. Third, we analyzed the results of the heat wave vulnerability assessment of Korea by administrative district.

\section{Methodology}

Vulnerability to climate change was assessed based on the methods defined in the IPCC's Fourth Assessment Report (AR4) [1]. In the AR4, vulnerability assessment is defined as a residual impact of climate change after adaptation. Vulnerability to climate change is the degree to which a system sensitively responds to climate change. The relative degree of vulnerability depends on different adaptation options based on future climate change scenarios. Equation (1) is used to assess vulnerability to climate change, as defined in the IPCC's AR4, using a weighted function of proxy variables including climate exposure, sensitivity, and adaptive capacity:

Vulnerability Index $=\alpha \times$ Climate Exposure Index $+\beta \times$ Sensitivity Index $-\gamma \times$ Adaptive Capacity Index $(\alpha, \beta, \gamma$ : weighting factor $)$

To assess vulnerability as defined in Equation (1), the conditions of the vulnerability assessment must be selected, and proxy variables must be identified and standardized. Additionally, a weighting factor must be assigned to each proxy variable. This process is described in detail in the following Sections 2.1-2.3.

\subsection{Selection of Vulnerability Assessment Conditions}

In this study, vulnerability assessment conditions were selected based on previous studies with consideration of the climatic and social characteristics of Korea. In this study, 237 reports and 106 papers 
were reviewed [30], focusing on the classification system of the United Kingdom Climate Impacts Program (UKCIP) and the Korean Climate Change Assessment Report 2010 (Technical Summary) published by the NIER [31]. Through this process, a total of 32 vulnerability assessment conditions (including health vulnerability to heat wave) in 7 categories (health, disaster and calamity, agriculture, forest, marine and fishery, water control, and ecosystem) were selected, as shown in Table 1.

Table 1. Vulnerability assessment conditions provided by the Vulnerability Assessment Tool to build Climate Change Adaptation Plan (VESTAP).

\begin{tabular}{|c|c|c|c|}
\hline Category & Condition & Category & Condition \\
\hline \multirow{9}{*}{ Health (9) } & Health vulnerability to flood & \multirow{3}{*}{ Water control (3) } & Vulnerability of water control \\
\hline & Health vulnerability to typhoon & & Vulnerability of irrigation \\
\hline & Health vulnerability to heat wave & & $\begin{array}{l}\text { Vulnerability of water quality and } \\
\text { aquatic ecology }\end{array}$ \\
\hline & Health vulnerability to cold wave & \multirow{3}{*}{ Ecosystem (3) } & Vulnerability of coniferous trees \\
\hline & $\begin{array}{l}\text { Health vulnerability to increase of } \\
\text { ozone concentration }\end{array}$ & & Vulnerability of insects \\
\hline & Health vulnerability to fine dust & & Vulnerability of national parks \\
\hline & $\begin{array}{l}\text { Health vulnerability to other } \\
\text { air contaminants }\end{array}$ & \multirow{5}{*}{ Agriculture (5) } & $\begin{array}{l}\text { Vulnerability of soil erosion } \\
\text { in farmland }\end{array}$ \\
\hline & $\begin{array}{l}\text { Vulnerability to infectious diseases } \\
\text { transmitted by insects and rodents }\end{array}$ & & $\begin{array}{l}\text { Vulnerability of cultivation/ } \\
\text { breeding facilities }\end{array}$ \\
\hline & $\begin{array}{l}\text { Health vulnerability to } \\
\text { waterborne diseases }\end{array}$ & & Vulnerability of rice productivity \\
\hline \multirow{7}{*}{ Forest (7) } & $\begin{array}{l}\text { Vulnerability of landslide by } \\
\text { localized torrential downpours }\end{array}$ & & Vulnerability of apple productivity \\
\hline & $\begin{array}{l}\text { Vulnerability of forest road } \\
\text { by landslide }\end{array}$ & & Vulnerability of livestock productivity \\
\hline & Vulnerability of forest fire & Marine/Fishery (1) & $\begin{array}{l}\text { Vulnerability of fisheries and } \\
\text { aquaculture to water } \\
\text { temperature change }\end{array}$ \\
\hline & $\begin{array}{l}\text { Vulnerability of pine trees to } \\
\text { diseases and pests }\end{array}$ & \multirow{4}{*}{ Disaster/Calamity (4) } & Vulnerability of infrastructure to flood \\
\hline & $\begin{array}{l}\text { Vulnerability of pine trees and } \\
\text { pine mushrooms }\end{array}$ & & $\begin{array}{l}\text { Vulnerability of infrastructure to } \\
\text { heat wave }\end{array}$ \\
\hline & Vulnerability of forest vegetation & & $\begin{array}{l}\text { Vulnerability of infrastructure to } \\
\text { cold wave }\end{array}$ \\
\hline & $\begin{array}{l}\text { Vulnerability of forest vegetation } \\
\text { to draught }\end{array}$ & & $\begin{array}{l}\text { Vulnerability of infrastructure to } \\
\text { sea-level rise }\end{array}$ \\
\hline
\end{tabular}

\subsection{Selection and Standardization of Proxy Variables}

In this section, the process of selecting and standardizing proxy variables for vulnerability assessment using 32 conditions in 7 categories is described. Proxy variables were chosen by literature survey and the AHP (Analytic Hierarchy Process) analysis method. First, a total of 237 reports and 106 articles were investigated and over 200 initial proxy variables were chosen [30]. Second, 3 levels of expert questionnaire for the AHP analysis method were conducted for more than 50 experts. Through this process, initial proxy variables have been reviewed and additional proxy variables were chosen. A total of 455 proxy variables were finally chosen from this list that seemed to adequately encompass the climate exposure, sensitivity, and adaptive capacity of Korea. The selected proxy variables were classified into 7 categories plus common variables: health (58), disaster and calamity (37), agriculture (68), forest (48), marine and fishery (43), water control (51), ecosystem (58), and common variables (92). Of the selected variables, proxy variables for climate exposure were extracted from RPC 4.5 and 8.5 scenarios that were refined based on the HadGEM2 model, and included future climate change projections, such as mean temperature. Proxy variables for sensitivity and adaptive capacity were extracted from indicators released by Statistics Korea (2005-2015); proxies 
for sensitivity included health, age, population, and regional productivity. Adaptive capacity proxy variables included gross regional domestic product (GRDP), financial independence, and the number of emergency medical centers (Table 2). The selected proxy variables were divided into 10-year intervals as follows: the 2000s (2001-2010), 2010s (2011-2020), 2020s (2021-2030), 2030s (2031-2040), and 2040s (2041-2050). At the same time, the proxy variables were divided, using a GIS-based system, into administrative units: provinces, municipalities, and submunicipalities.

The selected proxy variables need to be standardized in spatial units to apply them to Equation (1). The standardization process non-dimensionalizes proxy variables and is necessary when utilizing variables with different units. There are several methods of standardizing variables, such as $z$-score, re-scaling, and categorical scales. In this study, the standardization method suggested by Burton [32] was applied (Equation (2)).

$$
\frac{\text { Actual Value }- \text { Minimum Value }}{\text { Maximum Value - Minimum Value }}
$$

Table 2 shows 19 proxy variables, out of 455 total proxy variables, used to assess health vulnerability to heat waves. The 19 proxy variables fell into the components of climate exposure (7), sensitivity (6), and adaptive capacity (6). Climate exposure proxy variables are indices associated with actual and effective temperatures of heat waves, including heat wave duration and annual average value of daily maximum temperature. Sensitivity proxy variables are indices associated with vulnerable populations of those sensitive to heat waves, such as people aged 14 or younger, and those aged 65 or older. The number of deaths caused by heatstroke and sunstroke were included as sensitivity proxy variables, as these variables reflect the direct effects of a heat wave [1]. Adaptive capacity is the capacity to cope with health risk factors, and its proxy variables include indices associated with healthcare systems and socioeconomic factors.

\begin{tabular}{|c|c|c|c|c|}
\hline Component & Proxy Variable & Source & Data Type & Scale \\
\hline \multirow[t]{2}{*}{$\begin{array}{l}\text { Climate } \\
\text { exposure }\end{array}$} & $\begin{array}{l}\text { Annual average value of daily } \\
\text { maximum temperature } \\
\text { Number of days with daily maximum } \\
\text { temperature } \geq 33^{\circ} \mathrm{C} \\
\text { Number of days with daily minimum } \\
\text { temperature } \geq 25^{\circ} \mathrm{C} \\
\text { Daily relative humidity }\end{array}$ & \multirow{2}{*}{$\begin{array}{l}\text { RCP } 4.5,8.5 \text { Scenario of the } \\
\text { Korea Meteorological } \\
\text { Administration } \\
\text { (Detailed data of the Korean } \\
\text { Peninsula and South Korea, } \\
\text { and applied } \\
\text { meteorological data) }\end{array}$} & \multirow{4}{*}{ Vector (Polygon) } & \multirow{4}{*}{$\begin{array}{l}\text { Provinces } \\
\text { (Entire land of Korea) } \\
\text { Municipalities } \\
\text { (Si, Gun, Gu) } \\
\text { Submunicipalities } \\
\text { (Eup, Myeon, Dong) }\end{array}$} \\
\hline & $\begin{array}{l}\text { Heat wave duration index } \\
\text { Effective temperature } \\
\text { Discomfort index } \\
\text { (temperature-humidity index) }\end{array}$ & & & \\
\hline Sensitivity & $\begin{array}{l}\text { Population aged } 14 \text { or younger } \\
\text { Population aged } 65 \text { or older } \\
\text { Share of beneficiaries of national basic } \\
\text { livelihood guarantees } \\
\text { Share of the elderly population living } \\
\text { alone (aged } 65 \text { or older) } \\
\text { Number of deaths caused by } \\
\text { cardiovascular disorders } \\
\text { Number of deaths caused by } \\
\text { heatstroke/sunstroke }\end{array}$ & \multirow{2}{*}{$\begin{array}{l}\text { Statistics released by the } \\
\text { National Statistical Office }\end{array}$} & & \\
\hline $\begin{array}{l}\text { Adaptive } \\
\text { capacity }\end{array}$ & $\begin{array}{l}\text { GRDP healthcare services and } \\
\text { social services } \\
\text { Share of beneficiaries of } \\
\text { health insurance } \\
\text { Number of public health workers per } \\
\text { unit of population } \\
\text { Number of emergency } \\
\text { medical centers } \\
\text { Financial independence } \\
\text { Gross Regional Domestic } \\
\text { Product (GRDP) }\end{array}$ & & & \\
\hline
\end{tabular}

Table 2. Proxy variables for the assessment of health vulnerability to heat wave. 


\subsection{Weighting Factors of Proxy Variables}

In this study, weighting factors for proxy variables were selected through the following process based on previous studies conducted by the Korea Environmental Institute $[33,34]$ and the National Institute of Environmental Research (NIER) [31]. Yoo [33,34] investigated the selection of proxy variables and weighting factors in consideration of Korea's regional characteristics based on the vulnerability concept suggested by Moss [7]. That study extracted a total of 33 proxy variables and determined weighting factors using principle component analysis. Later, the NIER [31] conducted a detailed study on the selection of weighting factors using the analytic hierarchy process (AHP). In this study, a total of 32 vulnerability assessment conditions and weighting factors were selected based on previous studies. Table 3 shows the weighting factors of 19 proxy variables used for the assessment of health vulnerability to heat wave. In the assessment of health vulnerability to heat wave, the weighting factor of climate exposure was 0.5 , higher than those of sensitivity (0.25) and adaptive capacity (0.25). Of the 19 proxy variables, the weighting factor for "the number of days with daily maximum temperature $\geq 33^{\circ} \mathrm{C}^{\prime}$ was highest (0.26), followed by "the number of deaths caused by heatstroke/sunstroke" (0.24), and "the number of emergency medical centers" (0.16).

Table 3. Weighting factors of proxy variables for the assessment of health vulnerability to heat wave.

\begin{tabular}{|c|c|c|c|}
\hline Component & Weighting Factor & Proxy Variable & Weighting Factor \\
\hline \multirow{7}{*}{$\begin{array}{l}\text { Climate } \\
\text { exposure }\end{array}$} & \multirow{7}{*}{0.5} & Annual average value of daily maximum temperature & 0.11 \\
\hline & & Number of days with daily maximum temperature $\geq 33^{\circ} \mathrm{C}$ & 0.26 \\
\hline & & Number of days with daily minimum temperature $\geq 25^{\circ} \mathrm{C}$ & 0.1 \\
\hline & & Daily relative humidity & 0.13 \\
\hline & & Heat wave duration index (HWDI) & 0.15 \\
\hline & & Effective temperature & 0.1 \\
\hline & & Discomfort index (Temperature-humidity index) & 0.15 \\
\hline \multirow{6}{*}{ Sensitivity } & \multirow{6}{*}{0.25} & Population aged 14 or younger & 0.1 \\
\hline & & Population aged 65 or older & 0.2 \\
\hline & & Share of beneficiaries of national basic livelihood guarantees & 0.1 \\
\hline & & Share of the elderly population living alone (aged 65 or older) & 0.2 \\
\hline & & Number of deaths caused by cardiovascular disorders & 0.16 \\
\hline & & Number of deaths caused by heatstroke/sunstroke & 0.24 \\
\hline \multirow{6}{*}{$\begin{array}{l}\text { Adaptive } \\
\text { capacity }\end{array}$} & \multirow{6}{*}{0.25} & GRDP healthcare services and social services & 0.16 \\
\hline & & Share of beneficiaries of health insurance & 0.1 \\
\hline & & Number of public health workers per unit of population & 0.16 \\
\hline & & Number of emergency medical centers & 0.16 \\
\hline & & Financial independence & 0.21 \\
\hline & & Gross Regional Domestic Product (GRDP) & 0.21 \\
\hline
\end{tabular}

\section{Case Study (Assessment of Health Vulnerability to Heat Wave)}

This case study presents the results of an assessment of health vulnerability to heat waves at the province level in Korea. Later, health vulnerabilities at the municipality and submunicipality levels were also analyzed. Temporal assessment of health vulnerability to heat wave was conducted targeting the most distant future period (2040s) that is predictable under the RCP 8.5 scenario (assuming no effort to reduce emissions).

\subsection{Study Areas}

This case study targeted "Korea", "Daegu Metropolitan City", and "Seo-Gu, Daegu Metropolitan City" in stages. Daegu Metropolitan City was found to be the most vulnerable municipality through the first-stage assessment of vulnerability throughout Korea (province level). Figure 1 shows the target areas of this case study from the first to third stages. As shown in Figure 1a, Korea is divided into 14 provinces. Figure 2b shows the map of Daegu Metropolitan City, which is divided into seven municipalities. Figure 1c shows the 17 submunicipalities in Seo-Gu, Daegu Metropolitan City. 


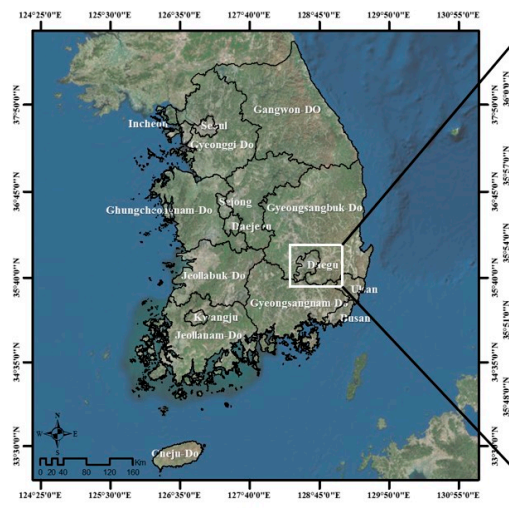

(a)

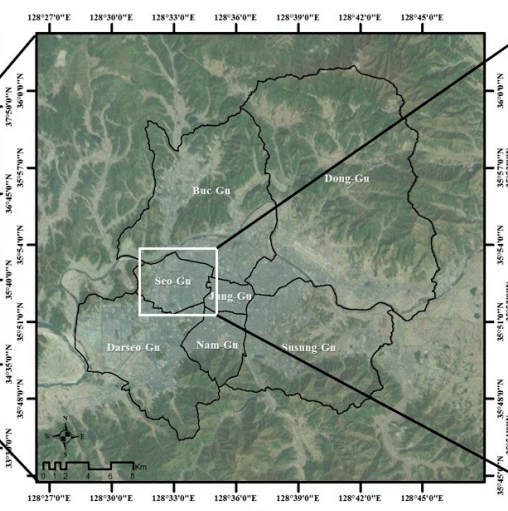

(b)

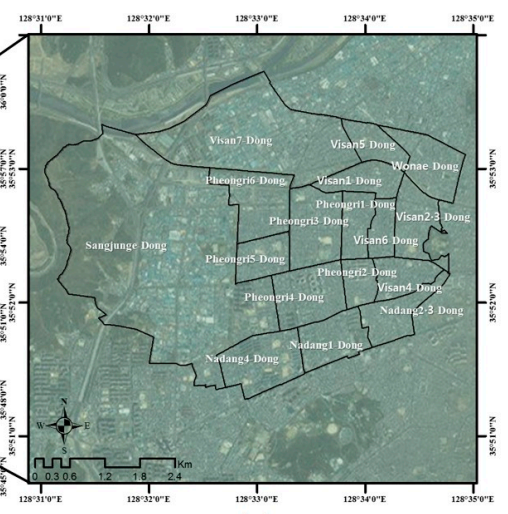

(c)

Figure 1. Study areas and assessment levels: (a) Korea; (b) Daegu Metropolitan City; (c) Seo-Gu, Daegu Metropolitan City.

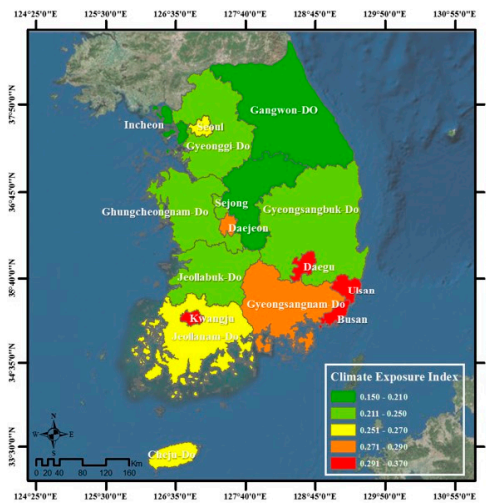

(a)

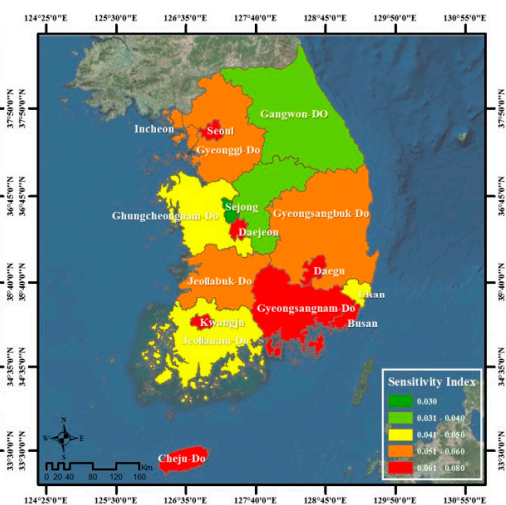

(b)

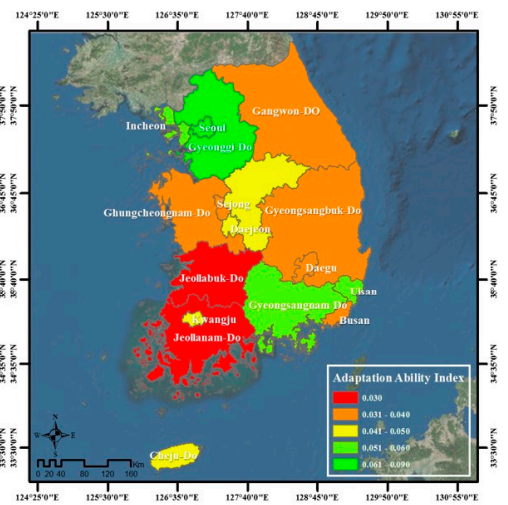

(c)

Figure 2. Climate exposure, sensitivity, and adaptive capacity indices of Korea in the 2040s: (a) climate exposure; (b) sensitivity; and (c) adaptive capacity.

Because this case study targets the assessment of health vulnerability to heat waves, it may be affected significantly by climatic factors subject to change depending on geographical and topographical characteristics. South Korea, the study area used for the first stage of analysis, is a peninsular country surrounded by water on three sides, and extends north from $33^{\circ} 06^{\prime} 40^{\prime \prime} \mathrm{N}$ latitude. As it is situated at a temperate latitude, Korea exhibits distinct regional and seasonal climate patterns. The annual average temperature in Korea is $10-15^{\circ} \mathrm{C}$. The maximum temperature occurs in July and August, when the average temperature ranges from $24-27^{\circ} \mathrm{C}$. According to the observations of the Korea Meteorological Administration in 2015, the maximum and minimum temperatures were $\sim 35.4{ }^{\circ} \mathrm{C}$ (July through August) and $-10.8^{\circ}$ (December through February). Daegu Metropolitan City, the study area of the second and third stages of the case study, is located in an inland area in southeast Korea at $35^{\circ} 36^{\prime}-36^{\circ} 01^{\prime} \mathrm{N}$ latitude and $128^{\circ} 21^{\prime}-128^{\circ} 46^{\prime} \mathrm{E}$ longitude. The city is in a basin surrounded by mountains with an average altitude of over $950 \mathrm{~m}$. Due to its topographical location, it is cold in winter and sweltering hot in summer, the characteristic climate of inland basins. According to data collected by the Korea Meteorological Administration in 2015, the average, maximum, and minimum temperatures in Daegu Metropolitan City were $14.7^{\circ} \mathrm{C}, 38.3^{\circ} \mathrm{C}$ (August), and $-8.9^{\circ} \mathrm{C}$ (February), respectively. The average temperature in August was the highest of any month $\left(26.0^{\circ} \mathrm{C}\right)$, and that of January was the lowest $\left(2.3^{\circ} \mathrm{C}\right)$. 


\subsection{Results}

At the first stage, assessment was conducted at the province level across the country. Figure 2 shows the indices of climate exposure, sensitivity, and adaptive capacity in the 2040s in each province. It concludes when the climate exposure and sensitivity indices are high and the adaptive capacity indices are low, the vulnerability to climate change is prone to be high. The results of climate exposure indices suggest that the southern coastal region will be more exposed than central inland areas. Daegu Metropolitan City has the highest climate exposure index of any province due to its topographical characteristics as an inland basin city. In terms of sensitivity, Seoul Metropolitan City, Gwangju Metropolitan City, Daegu Metropolitan City, and Jeju Province were more sensitive than other provinces and metropolitan cities, which is attributable to the large population aged 14 or younger and aged 65 or older, and the large number of deaths caused by cardiovascular disorders and sunstroke. Meanwhile, the share of beneficiaries of national basic livelihood guarantees and the portion of the elderly population living alone were high in North Jeolla Province, South Jeolla Province, and North Gyeongsang Province. This result is attributable to their relatively low urbanization rates and the large share of their populations working in primary industries. In terms of adaptive capacity, Seoul Metropolitan City, Ulsan Metropolitan City, and Gyeonggi Province were found to have relatively high adaptive capacity. The reason behind the results seems to be their high financial independence and gross regional domestic product (GRDP). Seoul Metropolitan City and Gyeonggi Province as the national capital region are the most densely populated areas in Korea, and Ulsan Metropolitan City is an industrial city with numerous large-scale facilities.

Figure 3 and Table 4 show the results of the assessment of health vulnerability to heat waves across Korea. The most vulnerable area at the province level was Daegu Metropolitan City, followed by Gwangju Metropolitan City, Busan Metropolitan City, Daejeon Metropolitan City, South Gyeongsang Province, and Ulsan Metropolitan City. Meanwhile, the least vulnerable area to heat wave at the province level was Gangwon Province, followed by Incheon Metropolitan City, North Chungcheong Province, Gyeonggi Province, and Sejong City. Daegu Metropolitan City had the highest vulnerability index, which is attributable to its high level of climate exposure caused by its topographical characteristics as a basin city and its low adaptive capacity. Gangwon Province, on the other hand, is mostly covered with mountains; its topographical characteristics result in low levels of climate exposure and sensitivity; thus, this province has a relatively low level of vulnerability. In this study, the factors that have the highest impact on the health vulnerability of Korean regions to heat waves were the proxy variables for climate exposure; this result is highly related to the weighting factors of proxy variables applied to this vulnerability assessment: climate exposure (0.5), sensitivity (0.25), and adaptive capacity (0.25) (Table 3). Thus, southern coastal areas (Daegu Metropolitan City, Gwangju Metropolitan City, Busan Metropolitan City, South Jeolla Province, South Gyeongsang Province, etc.), in which climate exposure indices were higher than in other regions, had high values for vulnerability indices. On the other hand, central inland areas (Gangwon Province, North Chungcheong Province, etc.), where climate exposure indices were relatively low, were found to have low vulnerability index values. Seoul Metropolitan City and Daejeon Metropolitan City, however, showed relatively high vulnerability indices, despite being located in the central region. This difference is caused by the heat island effect, which is stronger than in other provinces due to the high level of urbanization and the relatively large population of vulnerable people such as the elderly. 


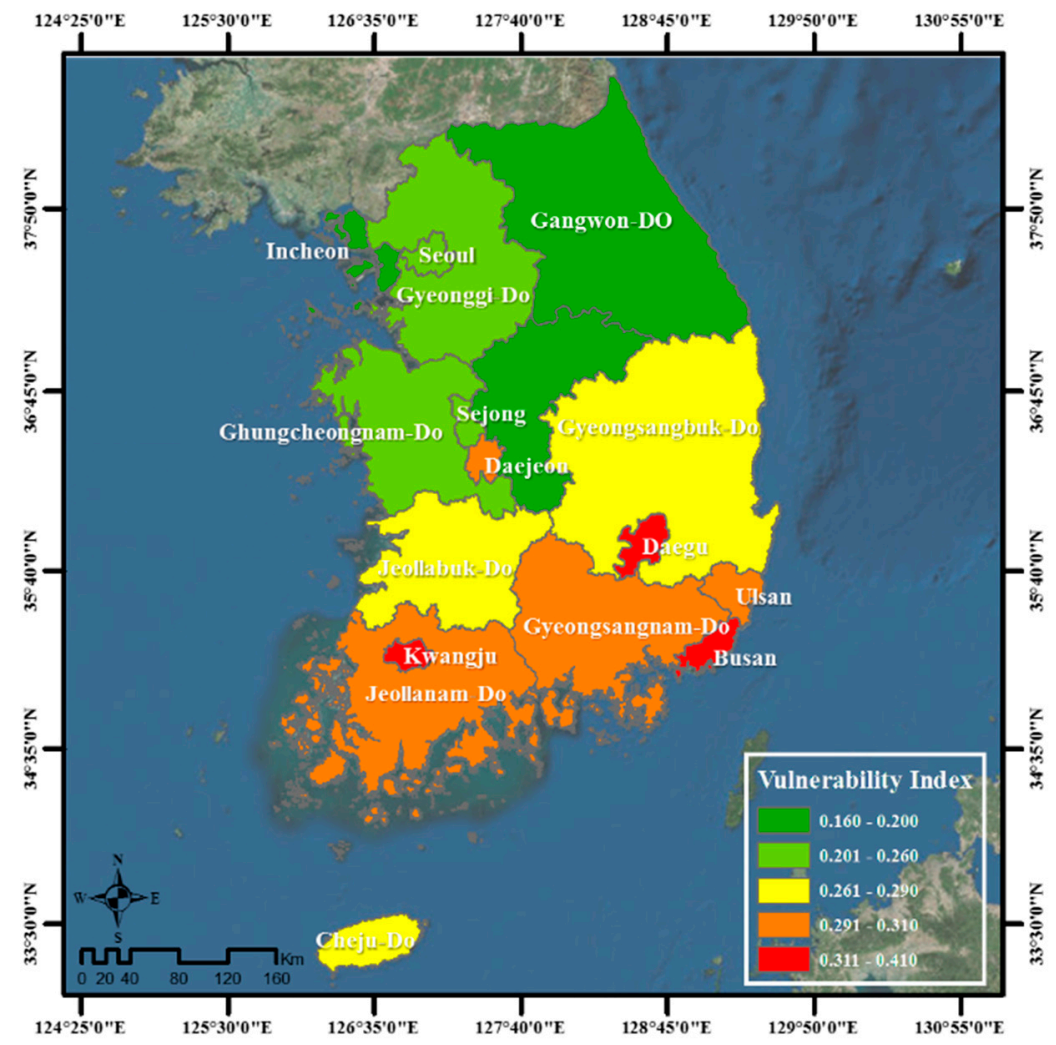

Figure 3. Health vulnerability assessment results to heat waves across South Korea in the 2040s.

Table 4. Vulnerability, climate exposure, sensitivity and adaptive capacity indices for each province.

\begin{tabular}{cccccc}
\hline Rank & Province & $\begin{array}{c}\text { Vulnerability } \\
\text { Index }\end{array}$ & $\begin{array}{c}\text { Climate Exposure } \\
\text { Index }\end{array}$ & $\begin{array}{c}\text { Sensitivity } \\
\text { Index }\end{array}$ & $\begin{array}{c}\text { Adaptive } \\
\text { Capacity Index }\end{array}$ \\
\hline 1 & Daegu Metropolitan City & 0.41 & 0.37 & 0.08 & 0.04 \\
2 & Gwangju Metropolitan City & 0.39 & 0.36 & 0.08 & 0.05 \\
3 & Busan Metropolitan City & 0.34 & 0.31 & 0.07 & 0.04 \\
4 & Daejeon Metropolitan City & 0.31 & 0.29 & 0.07 & 0.05 \\
5 & South Gyeongsang Province & 0.30 & 0.29 & 0.07 & 0.06 \\
6 & Ulsan Metropolitan City & 0.30 & 0.31 & 0.05 & 0.06 \\
7 & South Jeolla Province & 0.30 & 0.27 & 0.05 & 0.03 \\
8 & Jeju Province & 0.29 & 0.26 & 0.08 & 0.05 \\
9 & North Jeolla Province & 0.28 & 0.25 & 0.06 & 0.03 \\
10 & North Gyeongsang Province & 0.27 & 0.24 & 0.06 & 0.04 \\
11 & Seoul Metropolitan City & 0.26 & 0.26 & 0.08 & 0.08 \\
12 & South Chungcheong Province & 0.24 & 0.24 & 0.05 & 0.04 \\
13 & Sejong City & 0.24 & 0.25 & 0.03 & 0.04 \\
14 & Gyeonggi Province & 0.24 & 0.25 & 0.06 & 0.07 \\
15 & North Chungcheong Province & 0.20 & 0.21 & 0.04 & 0.05 \\
16 & Incheon Metropolitan City & 0.19 & 0.19 & 0.06 & 0.06 \\
17 & Gangwon Province & 0.16 & 0.15 & 0.04 & 0.04 \\
\hline
\end{tabular}

At the second stage of assessment, Daegu Metropolitan City, identified as the most vulnerable region in the first stage of assessment, was analyzed at the municipality level. Figure 4 shows the indices of climate exposure, sensitivity, and adaptive capacity for Daegu Metropolitan City in the 2040s at the municipality level. The climate exposure indices demonstrate that the closer to urbanized areas and the less green the area, the higher its level of climate exposure. Municipalities that showed the highest climate exposure indices were Seo-Gu, Jung-Gu, Buk-Gu, and Nam-Gu, which are urbanized areas close to Daegu City Hall and industrial complexes. In contrast to the climate exposure indices, municipalities such as Dong-Gu, Buk-Gu, and Dalseo-Gu were found to exhibit greater sensitivity than other areas. The reason for these results is that the values of variables associated with social 
vulnerability, such as the number of deaths caused by cardiovascular disorders, and the population aged 65 or older, were higher than in other municipalities. In terms of adaptive capacity, Nam-Gu and Seo-Gu were found to be vulnerable, while Dong-Gu, Jung-Gu, and Suseong-Gu had higher adaptive capacities. In the municipalities that had relatively high adaptive capacity, their GRDP was very high and the number of public health workers per unit of population was also relatively high.

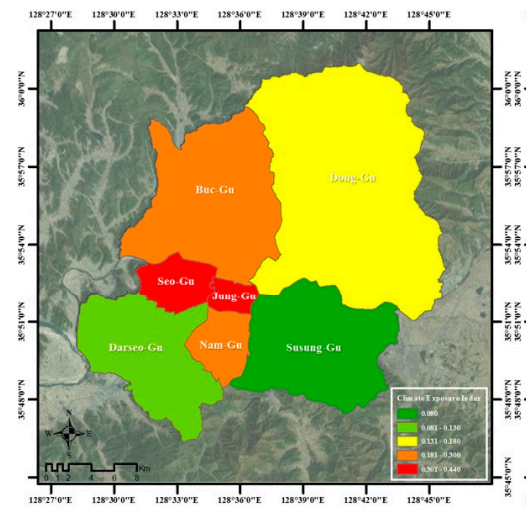

(a)

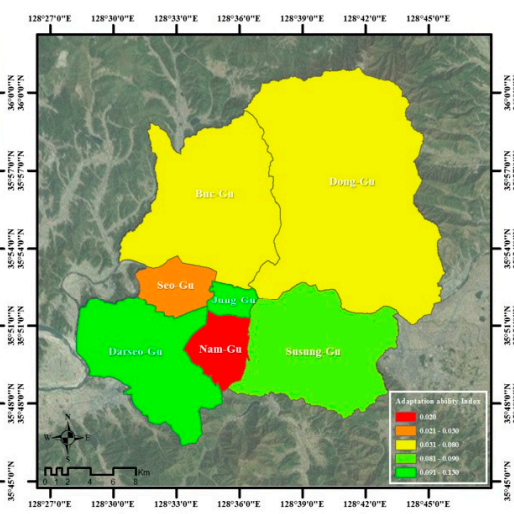

(b)

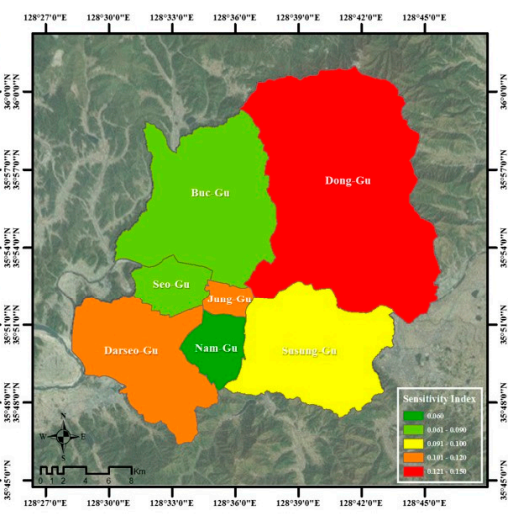

(c)

Figure 4. Climate exposure, sensitivity, and adaptive capacity of Daegu Metropolitan City in the 2040s: (a) climate exposure; (b) sensitivity; and (c) adaptive capacity.

Figure 5 and Table 5 show the results of health vulnerability assessments of the municipalities within Daegu Metropolitan City to heat wave. The most vulnerable municipality to heat wave was Seo-Gu, followed by Jung-Gu, Buk-Gu, and Nam-Gu. This result is attributable to their relatively higher climate exposure and sensitivity indices and the lower adaptive capacity index values of these areas compared with other municipalities.

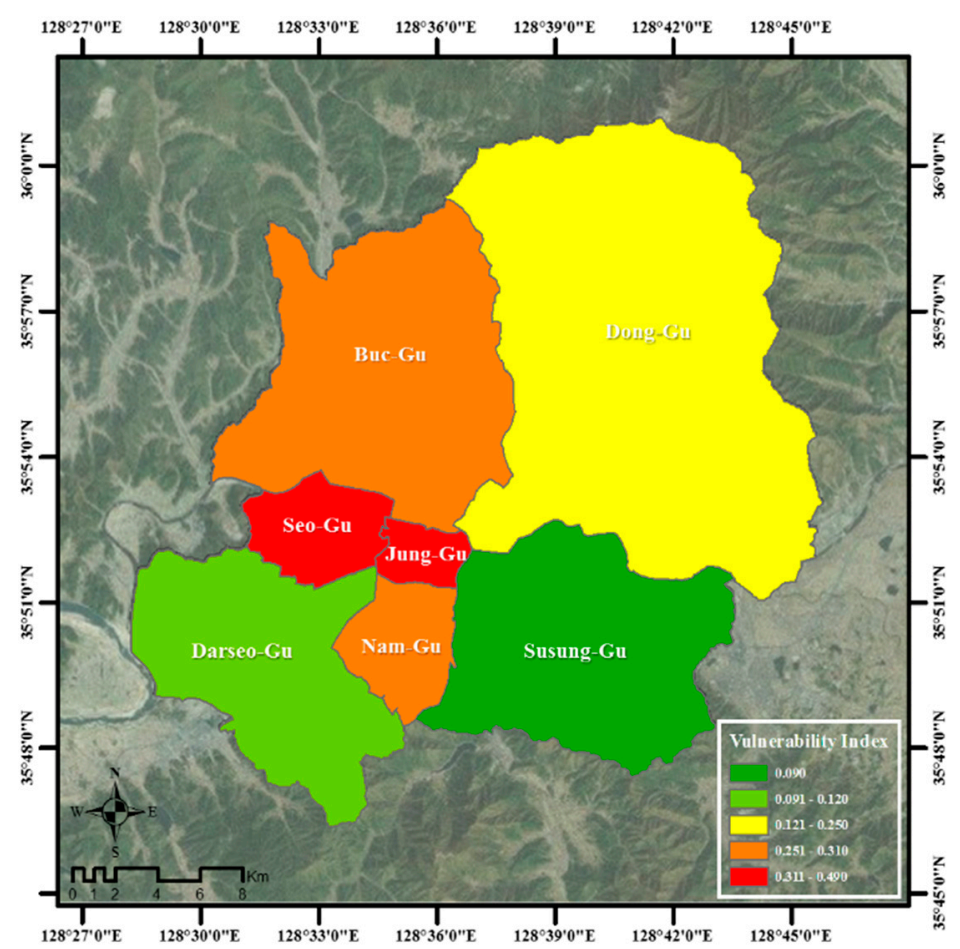

Figure 5. Health vulnerability assessment results for Daegu Metropolitan City to heat wave in the 2040s. 
Table 5. Vulnerability, climate exposure, sensitivity, and adaptive capacity indices of Daegu municipalities.

\begin{tabular}{cccccc}
\hline Rank & $\begin{array}{c}\text { Municipalities } \\
\text { (Si, Gun, Gu) }\end{array}$ & $\begin{array}{c}\text { Vulnerability } \\
\text { Index }\end{array}$ & $\begin{array}{c}\text { Climate Exposure } \\
\text { Index }\end{array}$ & $\begin{array}{c}\text { Sensitivity } \\
\text { Index }\end{array}$ & $\begin{array}{c}\text { Adaptive } \\
\text { Capacity Index }\end{array}$ \\
\hline 1 & Seo-Gu & 0.49 & 0.43 & 0.09 & 0.03 \\
2 & Jung-Gu & 0.45 & 0.44 & 0.12 & 0.11 \\
3 & Buk-Gu & 0.31 & 0.3 & 0.09 & 0.08 \\
4 & Nam-Gu & 0.3 & 0.26 & 0.06 & 0.02 \\
5 & Dalseong-Gu & 0.26 & 0.31 & 0.12 & 0.17 \\
6 & Dong-Gu & 0.25 & 0.18 & 0.15 & 0.08 \\
7 & Dalseo-Gu & 0.12 & 0.13 & 0.12 & 0.13 \\
8 & Suseong-Gu & 0.09 & 0.07 & 0.1 & 0.09 \\
\hline
\end{tabular}

During the third stage of assessment, Seo-Gu, Daegu Metropolitan City, the most vulnerable municipality in the second-stage assessment, was analyzed at the submunicipality level. Figure 6 shows the indices of climate exposure, sensitivity, and adaptive capacity of Seo-Gu in the 2040s at this level. Seo-Gu is located in the mid-western area of the city; its population density is higher than other districts and its share of green areas is very low. Submunicipalities that showed the highest climate exposure indices were Pyeongni 5-Dong, Pyeongni 3-Dong, Pyeongni 6-Dong, and Pyeongni 4-Dong, which are all densely populated areas near Daegu industrial complexes. In terms of sensitivity, however, unlike the results of climate exposure indices, submunicipalities such as Sangjungi-Dong, Bisan 7-Dong, Pyeongni 4-Dong, and Naedang 4-Dong were more sensitive than others due to greater populations aged 14 or younger and 65 or older, a large share of the elderly population living alone, and a high number of deaths caused by cardiovascular disorders, compared with other submunicipalities. In terms of adaptive capacity, eastern areas such as Pyeongni 5-Dong, Naedang 1-Dong, and Bisan 4-Dong were vulnerable, whereas Sangjungi-Dong had a high adaptive capacity. In the case of Sangjungi-Dong, GRDP healthcare services and social services, the number of public health workers per unit of population, and the GRDP were all higher than in other areas.

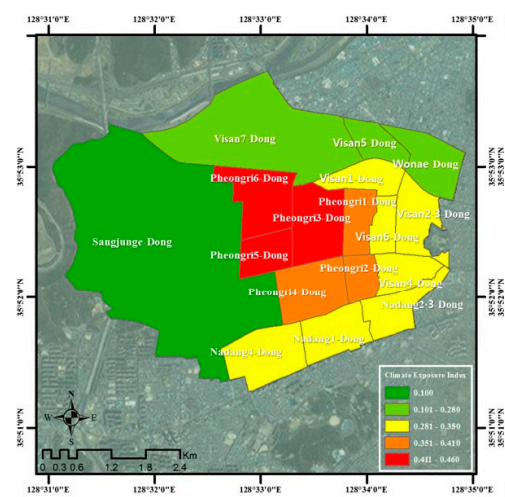

(a)

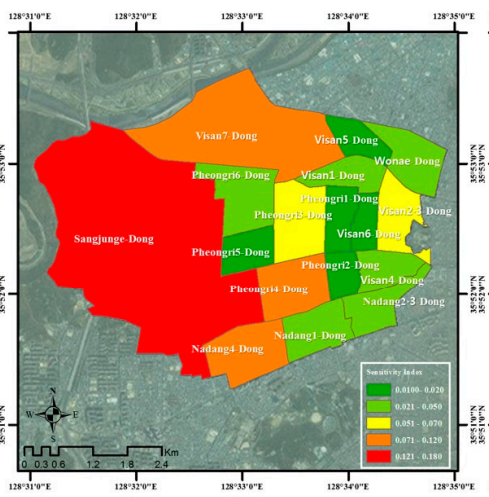

(b)

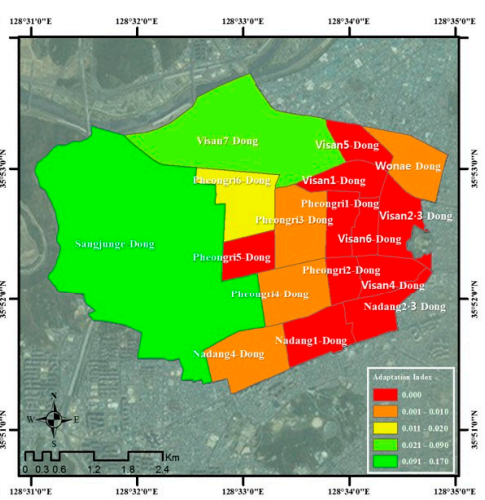

(c)

Figure 6. Climate exposure, sensitivity, and adaptive capacity maps of Seo-Gu, Daegu Metropolitan City in the 2040s: (a) climate exposure; (b) sensitivity; and (c) adaptive capacity.

Figure 7 and Table 6 show the health vulnerability assessment results of Seo-Gu submunicipalities to heat waves. The most vulnerable submunicipality was Pyeongni 3-Dong, followed by Pyeongni 4-Dong, Pyeongni 5-Dong, and Pyeongni 6-Dong. In addition, as Sangjungi-Dong's climate exposure index was lowest, and its sensitivity index was the highest, this submunicipality was identified as the most vulnerable. 


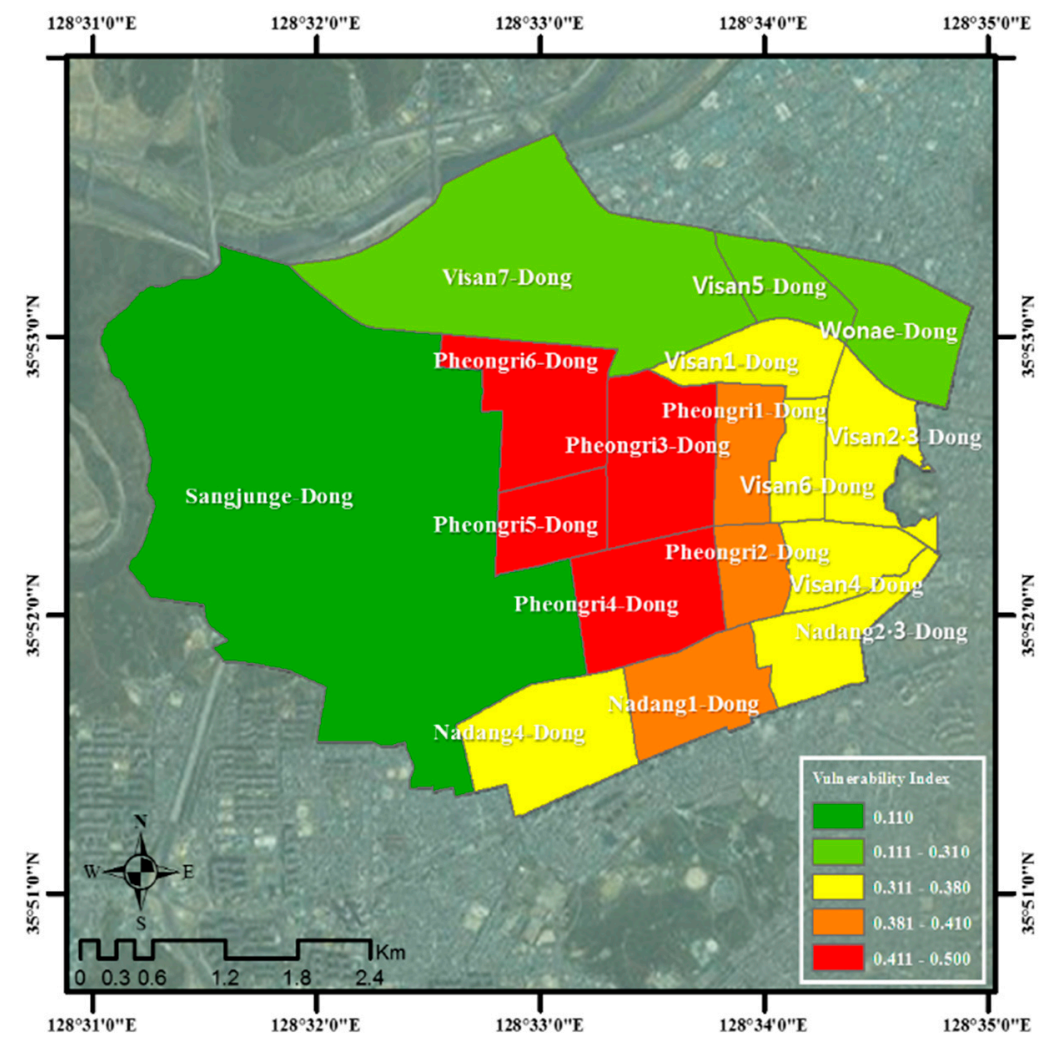

Figure 7. Health vulnerability assessment results for Seo-Gu, Daegu Metropolitan City to heat waves in the 2040s.

Table 6. Vulnerability, climate exposure, sensitivity, and adaptive capacity indices of Seo-Gu submunicipalities.

\begin{tabular}{cccccc}
\hline Rank & $\begin{array}{c}\text { Submunicipality } \\
\text { (Eup, Myeon, Dong) }\end{array}$ & $\begin{array}{c}\text { Vulnerability } \\
\text { Index }\end{array}$ & $\begin{array}{c}\text { Climate Exposure } \\
\text { Index }\end{array}$ & $\begin{array}{c}\text { Sensitivity } \\
\text { Index }\end{array}$ & $\begin{array}{c}\text { Adaptive Capacity } \\
\text { Index }\end{array}$ \\
\hline 1 & Pyeongni 3-Dong & 0.5 & 0.45 & 0.06 & 0.01 \\
2 & Pyeongni 4-Dong & 0.49 & 0.41 & 0.09 & 0.01 \\
3 & Pyeongni 5-Dong & 0.47 & 0.46 & 0.01 & 0 \\
4 & Pyeongni 6-Dong & 0.45 & 0.44 & 0.03 & 0.02 \\
5 & Pyeongni 1-Dong & 0.41 & 0.39 & 0.02 & 0 \\
6 & Pyeongni 2-Dong & 0.4 & 0.39 & 0.01 & 0 \\
7 & Naedang 1-Dong & 0.39 & 0.35 & 0.04 & 0.01 \\
8 & Naedang 4-Dong & 0.38 & 0.3 & 0.09 & 0 \\
9 & Bisan 2-3-Dong & 0.37 & 0.3 & 0.07 & 0 \\
10 & Bisan 4-Dong & 0.37 & 0.33 & 0.04 & 0 \\
11 & Bisan 1-Dong & 0.36 & 0.32 & 0.04 & 0 \\
12 & Naedang 2-3-Dong & 0.36 & 0.31 & 0.05 & 0.01 \\
13 & Bisan 6-Dong & 0.35 & 0.34 & 0.12 & 0.01 \\
14 & Bisan 7-Dong & 0.31 & 0.28 & 0.05 & 0 \\
15 & Wondae-Dong & 0.29 & 0.25 & 0.02 & 0.17 \\
16 & Bisan 5-Dong & 0.27 & 0.25 & 0.18 & 0.13 \\
17 & Sangjungi-Dong & 0.11 & 0.1 & & \\
\hline
\end{tabular}

Through comprehensive analysis of the results of the three assessment stages, Pyeongni 3-Dong in Seo-Gu, Daegu Metropolitan City was the most vulnerable location in South Korea. We also found that proxy variables for climate exposure such as the number of days with daily maximum temperature $\geq 33^{\circ} \mathrm{C}$, daily relative humidity, and effective temperature had relatively large impacts on the results. In particular, the number of days with daily maximum temperature $\geq 33{ }^{\circ} \mathrm{C}$ and daily relative humidity were two key factors. In terms of sensitivity proxy variables, the contributions of 
the share of beneficiaries of national basic livelihood guarantees and the population aged 65 or older were highest, followed by the share of the elderly population living alone. These results indicate that the relative sizes of healthy and socioeconomically vulnerable populations in a local community are closely related to the sensitivity of health vulnerability to a heat wave. In terms of proxy variables for adaptive capacity, the share of beneficiaries of health insurance and the number of public health workers per unit of population were major drivers. These results show that it is necessary to improve the medical infrastructure of local communities rather than increase measures of overall economic capacity, such as financial independence or GRDP, to increase the adaptive capacity associated with health vulnerability to heat waves.

\section{Discussion and Conclusions}

It is essential to conduct a standardized vulnerability assessment to climate change, and to develop proper countermeasures against climate change based on the assessment's results. To establish more reliable and realistic adaptation measures, it is necessary to comprehensively assess and analyze a wide range of variables. In addition, measures need to be developed by taking into account the different characteristics of small regional segments based on the data analyzed, such as those presented here. All these efforts put into this study will contribute to sustainable development which can reduce climate change vulnerability. In this study, the methodologies used in previous studies of vulnerability to climate change were further refined to develop the Korean climate change vulnerability assessment tool, VESTAP. VESTAP can be used to assess vulnerability to climate change in Korea by selecting different spatial ranges from provinces to municipalities or submunicipalities. In addition, VESTAP was developed with RPC 4.5 and 8.5 scenarios; thus, vulnerability to climate change can be analyzed from the 2000s to the 2040s in 10-year increments. To demonstrate a case study of vulnerability assessment using VESTAP, an assessment of health vulnerability to heat waves was conducted across South Korea under the RCP 8.5 scenario, targeting the 2040s; its results indicated that Pyeongni 3-Dong in Seo-Gu, Daegu Metropolitan City was the most vulnerable location in Korea to heat waves. Meanwhile, the distributions of vulnerability and climate exposure indices were nearly identical in all assessments at the levels of provinces, municipalities, and submunicipalities, indicating that the contribution of climate exposure to heat wave threat is higher than that of sensitivity or adaptive capacity. Thus, it is necessary to establish policies for climate change adaptation that account for regional differences in climate exposure.

This study is significant in that it lays the foundation for standardized assessment of vulnerability to climate change in Korea. In addition, VESTAP provides sequential evaluation results based on Korean administrative district units, and is therefore a useful tool for policy makers. However, establishing new proxy variables not reflected in the indices or setting weights on regional characteristics could reveal more accurate vulnerability assessment. Also, frequent updating of data set for VESTAP is required, which will enhance the reliability of the result.

Acknowledgments: This research was conducted at Korea Environment Institute (KEI) with support by a grant (16CTAP-C114629-01) from the Technology Advancement Research Program (TARP) funded by the Ministry of Land, Infrastructure and Transport of the Korean government.

Author Contributions: Moung-Jin Lee conceived and designed the experiments; Kwan-Young Oh performed the experiments; Seong-Woo Jeon analyzed the data; Moung-Jin Lee and Kwan-Young Oh wrote the paper.

Conflicts of Interest: The authors declare no conflict of interest.

\section{References}

1. Intergovernmental Panel on Climate Change (IPCC). Climate Change 2013: The Physical Science Basis: Working Group I Contribution to the Fifth Assessment Report of the Intergovernmental Panel on Climate Change; Cambridge University Press: Cambridge, UK, 2013; pp. 1-40.

2. Intergovernmental Panel on Climate Change (IPCC). Climate Change 2014: Impacts, Adaptation, and Vulnerability; Cambridge University Press: Cambridge, UK, 2014; pp. 1-32. 
3. Intergovernmental Panel on Climate Change (IPCC). Climate Change 2007: Impacts, Adaptation and Vulnerability; Cambridge University Press: Cambridge, UK, 2007; pp. 1-30.

4. Füssel, H.T. Vulnerability: A generally applicable conceptual framework for climate change research. Glob. Environ. Chang. 2007, 17, 155-167. [CrossRef]

5. Bolin, B.A. History of the Science and Politics of Climate Change; Cambridge University Press: Cambridge, UK, 2007; pp. 1-42.

6. Houghton, J.T.; Meira Filho, L.G.; Lim, K.; Trennton, I.; Mamaty, I.; Bonduki, Y.; Griggs, D.J.; Callander, B.A. Revised 1996 IPCC Guidelines for National Greenhouse Gas Inventories: Intergovernmental Panel on Climate Change; Cambridge University Press: Cambridge, UK, 1997; pp. 1-40.

7. Moss, R.H.; Brenkert, A.L.; Malone, E.L. Vulnerability to Climate Change. A Quantitative Approach. Available online: http://www.globalchange.umd.edu/data/publications/Vulnerability_to_Climate_ Change.PDF (accessed on 19 June 2017).

8. Brooks, N.; Adger, W.N.; Kelly, P.M. The determinants of vulnerability and adaptive capacity at the national level and the implications for adaptation. Glob. Environ. Chang. 2005, 15, 151-163. [CrossRef]

9. Engle, N.L. Adaptive capacity and its assessment. Glob. Environ. Chang. 2011, 21, 647-656. [CrossRef]

10. Smit, B.; Wandel, J. Adaptation, adaptive capacity and vulnerability. Glob. Environ. Chang. 2006, 16, $282-292$. [CrossRef]

11. Moss, R.H.; Edmonds, J.A.; Hibbard, K.A.; Manning, M.R.; Rose, S.K.; van Vuuren, D.P.; Meehl, G.A. The next generation of scenarios for climate change research and assessment. Nature 2010, 463, 747-756. [CrossRef] [PubMed]

12. Füssel, H.M.; Klein, R.J. Climate change vulnerability assessments: An evolution of conceptual thinking. Clim. Chang. 2006, 75, 301-329. [CrossRef]

13. Kasperson, R.E.; Jeanne, X.K. Climate Change, Vulnerability, and Social Justice; Stockholm Environment Institute: Stockholm, Sweden, 2001; pp. 1-30.

14. United Nations Framework Convention on Climate Change (UNFCCC). Climate Change: Impacts, Vulnerabilities and Adaptation in Developing Countries; UNFCCC: Bonn, Germany, 2007; pp. 1-30.

15. Schipper, L.; Liu, W.; Krawanchid, D.; Chanthy, S. Review of Climate Change Adaptation Methods and Tools. Available online: http:/ /www.mrcmekong.org/assets/Publications/technical/Tech-No34-Reviewof-climate-change.pdf (accessed on 19 June 2017).

16. Harrison, P.A.; Holman, I.P.; Berry, P.M. Assessing cross-sectoral climate change impacts, vulnerability and adaptation: An introduction to the CLIMSAVE project. Clim. Chang. 2015, 128, 153-167. [CrossRef]

17. Rosenzweig, C.; Solecki, W.D.; Hammer, S.A.; Mehrotra, S. (Eds.) Climate Change and Cities: First Assessment Report of the Urban Climate Change Research Network; Cambridge University Press: Cambridge, UK, 2011; pp. 1-40.

18. Baker, J.L. (Ed.) Climate Change, Disaster Risk, and the Urban Poor: Cities Building Resilience for a Changing World; World Bank Publications: Washington, DC, USA, 2012; pp. 1-35.

19. Patz, J.A.; Campbell-Lendrum, D.; Holloway, T.; Foley, J.A. Impact of regional climate change on human health. Nature 2005, 438, 310-317. [CrossRef] [PubMed]

20. Haines, A.; Kovats, R.S.; Campbell-Lendrum, D.; Corvalán, C. Climate change and human health: Impacts, vulnerability and public health. Public Health 2006, 120, 585-596. [CrossRef] [PubMed]

21. Coumou, D.; Rahmstorf, S. A decade of weather extremes. Nat. Clim. Chang. 2012, 2, 491-496. [CrossRef]

22. Hess, J.J.; McDowell, J.Z.; Luber, G. Integrating climate change adaptation into public health practice: Using adaptive management to increase adaptive capacity and build resilience. Environ. Health Perspect. 2012, 120, 171-179. [CrossRef] [PubMed]

23. Fouillet, A.; Rey, G.; Laurent, F.; Pavillon, G.; Bellec, S.; Guihenneuc-Jouyaux, C.; Hémon, D. Excess mortality related to the August 2003 heat wave in France. Int. Arch. Occup. Environ. Health 2016, 80, 16-24. [CrossRef] [PubMed]

24. Pengelly, L.D.; Campbell, M.E.; Cheng, C.S.; Fu, C.; Gingrich, S.E.; Macfarlane, R. Anatomy of heat waves and mortality in Toronto, Lessons for public health protection. Can. J. Public Health 2007, 98, 364-368. [PubMed]

25. Robine, J.M.; Cheung, S.L.K.; le Roy, S.; van Oyen, H.; Griffiths, C.; Michel, J.P.; Herrmann, F.R. Death toll exceeded 70,000 in Europe during the summer of 2003. C. R. Biol. 2008, 331, 171-178. [CrossRef] [PubMed]

26. Revich, B.A. Heat-wave, air quality and mortality in European Russia in summer 2010: Preliminary assessment. Ekol. Cheloveka Hum. Ecol. 2011, 7, 3-9. 
27. Kysely, J.; Kim, J. Mortality during heat waves in South Korea, 1991 to 2005: How exceptional was the 1994 heat wave? Clim. Res. 2009, 38, 105-116. [CrossRef]

28. Fouillet, A.; Rey, G.; Wagner, V.; Laaidi, K.; Empereur-Bissonnet, P.; le Tertre, A.; Frayssinet, P.; Bessemoulin, P.; Laurent, F.; de Crouy-Chanel, P.; et al. Has the impact of heat waves on mortality changed in France since the European heat wave of summer 2003? A study of the 2006 heat wave. Int. J. Epidemiol. 2008, 37, 309-317. [PubMed]

29. Park, J.E.; Heo, B.Y.; Sunwoo, Y. A Study on Human Damage due to Heat Wave by Region. J. Korean Soc. Hazard Mitig. 2016, 16, 103-109. [CrossRef]

30. Korea Environmental Institute (KEI). Establishment of Climate Change Adaptation Information Utilization System; KEI Press: Sejong, Korea, 2014.

31. National Institute of Environmental Research (NIER). Climate Change Vulnerability Maps for Local Climate Change Adaptation Planning; NIER Press: Incheon, Korea, 2012.

32. Burton, I.; Development Programme United Nations. Adaptation Police Framework for Climate Change Developing Strategies; Cambridge University Press: Cambridge, UK, 2005.

33. Yoo, G.Y.; Park, S.W.; Chung, D.K.; Kang, H.J.; Hwang, J.H. Development and application of a methodology for climate change vulnerability assessment-Sea level rise impact on a coastal city. Environ. Policy Res. 2010, 9, 185-205.

34. Yoo, G.Y.; Kim, I.H. Development and Application of a Climate Change Vulnerability Index; KEI Press: Sejong, Korea, 2008.

(C) 2017 by the authors. Licensee MDPI, Basel, Switzerland. This article is an open access article distributed under the terms and conditions of the Creative Commons Attribution (CC BY) license (http:/ / creativecommons.org/licenses/by/4.0/). 